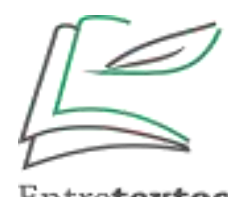

Entretextos 21(3): especial, 2021

ISSN (digital): 2764-0809

ISSN (impresso): 1519-5392

DOI: $10.5433 / 1519-5392.2021 v 21$ n3Esp.p218

\title{
Desvios colocacionais em português língua estrangeira
}

\author{
Collocational deviations in Portuguese as a foreign language \\ Desviaciones de colocación en portugués como lengua extranjera
}

José William da Silva Netto ${ }^{1}$ (iD https://orcid.org/0000-0003-0892-9933

\begin{abstract}
RESUMO: Este artigo objetiva discutir os desvios colocacionais evidenciados em produções textuais em Português Língua Estrangeira (doravante PLE), como forma de revelar as hipóteses levantadas pelos aprendizes acerca do funcionamento da língua portuguesa. Em nossos referenciais teóricos, destacamos os estudos sobre colocações, na perspectiva fraseológica, em Sinclair (1991), Lewis (2000, 2012), Bahns (1993) e Tagnin (2013), o conceito de competência colocacional de Lewis (2000), Wu (2003) e O'Dell e McCarthy (2008), e os cinco processos de interlíngua de Selinker (1974), Henderson (1985) e Tarone (2006). Nossa metodologia contempla cinco propostas de produções de texto, do gênero e-mail, cujo teor aborda as perspectivas dos participantes sobre aspectos culturais brasileiros, como a culinária e os pontos turísticos. Os participantes, por sua vez, são oito norte-americanos que desenvolveram atividades de promoção da língua inglesa no Brasil por nove meses em 2015. As produções textuais dos participantes foram analisadas, as ocorrências de desvios colocacionais identificadas e classificadas conforme os seus níveis de proficiência, a saber B1/B2 e C1/C2. Os dados revelaram que os desvios são, em sua maioria, motivados pelos processos de transferência linguística e de emprego equivocado de elementos verbais e nominais, e mais recorrentes nos níveis mais avançados de proficiência em PLE.
\end{abstract}

PALAVRAS-CHAVE: Colocações. Interlíngua. Português Língua Estrangeira.

ABSTRACT: This paper's purpose is to discuss the collocational deviations evidenced in Portuguese as a Foreign Language (hereinafter PFL) written texts as a means to reveal the learners' hypotheses on how the Portuguese language functions. Our theoretical background highlights the studies on collocations, from a phraseological perspective, by Sinclair (1991), Lewis (2000, 2012), Bahns (1993) and Tagnin (2013), the concept of collocational competence by Lewis (2000), Wu (2003) and O'Dell and McCarthy (2008), and the five interlanguage processes by Selinker (1974), Henderson (1985) and Tarone (2006). Our methodology includes five written

\footnotetext{
${ }^{1}$ Doutor em Linguística (UFC-CE). Professor da Casa de Cultura Britânica - UFC, Centro de Humanidades, Fortaleza, Ceará. E-mail: williamnettoo@gmail.com.
} 
assignments, in an e-mail genre, whose context addresses the participants' perspectives on Brazilian cultural aspects, such as cuisine and tourist attractions. The participants, in turn, are eight North Americans who promoted the English language in Brazil for nine months in 2015. The text productions were analyzed, the collocational deviation occurrences were identified and classified according to the participants' proficiency levels, namely B1/B2 and C1/C2. The data revealed that the deviations are mostly motivated by two interlanguage processes, language transfer and misuse of verbal and nominal elements, and are recurrent in the more advanced levels of proficiency in PFL.

KEYWORDS: Collocations. Interlanguage. Portuguese as a Foreign Language.

RESUMEN: Este articulo tiene como objetivo discutir las desviaciones de colocación que se evidencian en las producciones textuales en portugués como lengua extranjera (en adelante PLE), como una forma de revelar las hipótesis planteadas por los estudiantes sobre el funcionamiento de la lengua portuguesa. Nuestras referencias teóricas incluyen las colocaciones, en la perspectiva fraseológica, en Sinclair (1991), Lewis (2000, 2012) y Tagnin (2013), el concepto de competencia colocaciones de Lewis (2000) y Wu (2003), y los procesos de interlengua de Selinker (1974), Henderson (1985) y Tarone (2006). Nuestra metodología incluye cinco propuestas para producciones de texto, del género e-mail, sobre aspectos culturales brasileños, como la gastronomía y los atractivos turísticos. Los participantes, a su vez, son ocho norteamericanos que desarrollaron actividades para promover el idioma inglés en Brasil durante nueve meses en 2015. Se analizaron las producciones textuales de los participantes, se identificaron las ocurrencias de desviaciones de colocaciones y se clasificaron según sus niveles de competencia, es decir, B1/B2 and $\mathrm{C} 1 / \mathrm{C} 2$. Los datos revelaron que las desviaciones están motivadas en su mayoría por los procesos de transferencia lingüística y mal uso de elementos verbales y nominales, y más recurrentes en los niveles más avanzados de competencia en PLE.

PALABRAS CLAVE: Colocaciones. Interlengua. Portugués como Lengua Extranjera.

\section{Introdução}

O Português brasileiro se encontra em processo de globalização, observável a partir de três esferas, a saber, a econômica, nas relações de mercado que o Brasil detém com outros países e no desenvolvimento comercial evidenciado nas últimas décadas, a cultural, no crescente interesse de estrangeiros pela música, costumes, culinária e esporte, entre outros, decorrendo no alto volume de turistas que visitam o território nacional, e a educacional, na qual não só a procura de universidades brasileiras por alunos imigrantes vem crescendo ao longo dos anos, mas também o interesse pelo exame de proficiência Celpe-Bras. Partindo da última esfera, as pesquisas linguísticas sobre 0 Português como Língua Estrangeira (doravante PLE) tomam corpo, cujo escopo abrange desde o ensino e aprendizagem da língua, até as questões sobre as políticas linguísticas subjacentes à internacionalização do Português.

Nesse contexto, e partindo do projeto de pesquisa intitulado Políticas Linguísticas 
para a Internacionalização do Português (PLIP - Universidade Federal do Ceará), tratamos, dentre outros temas, da aprendizagem de fraseologismos em PLE, como as expressões idiomáticas e as colocações, assumindo que esses itens lexicais desempenham papel fundamental nos discursos que permeiam as interações comunicativas e cuja aprendizagem é indispensável no âmbito de língua estrangeira (doravante LE). Do mesmo modo, esse artigo deriva de nossa dissertação, na qual investigamos a forma como estrangeiros produzem colocações em textos escritos.

Nossa contribuição para o campo do PLE é dada com base no estudo dos desvios colocacionais localizados em produções textuais de falantes não-nativos, cujo fenômeno descreve a maneira como o léxico da língua portuguesa é aprendido por estrangeiros e também revela as hipóteses levantadas pelos participantes sobre o funcionamento da língua. Assim, centramo-nos na noção de competência comunicativa apresentada por Hymes (1972), na qual a competência colocacional de Lewis (2000) se inscreve, e nos processos de interlíngua de Selinker (1974).

O nosso corpus é composto por produções escritas de oito norte-americanos falantes de PLE, de níveis intermediário e avançado, nas quais os desvios colocacionais foram evidenciados e classificados. Os manuscritos foram produzidos ao longo dos nove meses de estada no Brasil, durante os quais os participantes desenvolveram atividades de promoção da língua inglesa em universidades brasileiras.

\section{A competência colocacional e a noção de desvio linguístico}

O termo colocação pode ser definido a partir de diferentes perspectivas, como a da Terminologia e a da Fraseologia. Para este artigo, interessa-nos situar essa unidade lexical como objeto de estudo fraseológico, cuja relevância é crucial para a aprendizagem de LE, haja vista que, "[...] em média, $70 \%$ de tudo que falamos, ouvimos, lemos ou escrevemos está disposto em algum tipo de expressão lexicalizada2" (LEWIS, 2000, p. 52, tradução nossa). Outrossim, o papel desempenhado pelas colocações nos mais variados discursos em sociedade chancela a sua importância no âmbito do ensino e aprendizagem.

A literatura especializada define o termo como "[...] a forma como palavras

\footnotetext{
${ }^{2}[\ldots]$ up to $70 \%$ of everything we say, hear, read, or write is to be found in some form of fixed expression.
} 
distintas co-ocorrem com outras ${ }^{3 "}$ (LEWIS, 2012, p. 93, tradução nossa), e "[...] a maneira como palavras co-ocorrem em textos autênticos de forma estatisticamente significante $^{4 \prime \prime}$ (LEWIS, 2000, p. 132, tradução nossa). Sobre essas definições, destacamos que o termo frequência, em nosso artigo, figura não como uma equivalência entre todas as palavras presentes no léxico de uma língua, a fim de definí-las como mais ou menos frequentes, mas sim na periodicidade na qual elas são encontradas em associação com outras palavras, como em combinações mais recorrentes - fazer e feio/sexo/a diferença - e colocações mais restritas - velha coroca.

Sinclair (1991, p. 115, tradução nossa, grifo do autor) as classifica com base nos seus elementos, "[...] utilizando o termo base para a palavra que está sendo estudada, e o termo colocado para qualquer palavra que ocorra juntamente com a base em um contexto específico5". Suplementarmente, as colocações pertencem a um continuum de diferentes graus de combinabilidade e de lexicalização (LEWIS, 2012), descrito por Carter (1987) em quatro categorias, quais sejam, (a) não restritas, as quais acomodam palavras que não formam colocações; (b) semi restritas, compostas por elementos que combinam com um número menor de palavras e cujos colocados podem ser substituídos, como em um par de sapato/meia; (c) familiares, cujos elementos coocorrem de forma frequente, porém não exclusiva; e (d) restritas, ou colocações fixas, cujos elementos não podem ser alterados, tal como em velha coroca. Assim, as combinações não restritas correspondem as associações livres de palavras, ao passo que as semi restritas, as familiares e as restritas se configuram como colocações por "[...] refletirem o significado de suas partes constituintes e por serem utilizadas frequentemente, por saltarem à mente de forma rápida e por serem psicologicamente salientes ${ }^{6 \prime \prime}$ (BAHNS, 1993, p. 57, tradução nossa).

Sobre as suas estruturas sintáticas, Tagnin (2013) as classifica em (a) adjetivas, as quais "[...] reúne $(\mathrm{m})$ estruturas do tipo [adjetivo + substantivo], tanto o adjetivo quanto o substantivo podem ser convencionados" (TAGNIN, 2013, p. 64, grifo nosso), como em má sorte, (b) nominais, elencam as "[...] colocações que são formadas por dois substantivos, dos quais pelo menos um, o colocado, é convencionado; por vezes os dois

\footnotetext{
${ }^{3}[\ldots]$ the way individual words co-occur with others.

4 [...] the way in which words co-occur in natural text in statistically significant ways.

5 [...] using the term node for the word that is being studied, and the term collocate for any word that occurs in the specified environment of a node.

${ }^{6}[\ldots]$ reflect the meaning of their constituent parts and that they are used frequently, spring to mind readily, and are psychologically salient.
} 
o são" (TAGNIN, 2013, p. 65), como em bicabornato de sódio, (c) verbais, são combinações cujo primeiro elemento é um verbo e servem de termo guarda-chuva para as estruturas com verbo de suporte e locuções verbais (HUNDT, 1994), como em fazer um elogio, (d) adverbiais, cujo advérbio modifica o adjetivo - expressamente proibido, ou o verbo - chorar copiosamente -, (e) especificadoras de unidade, denotam valor partitivo - uma barra de sabão/chocolate -, e (f) coletivas, cujas palavras são "[...] convencionalmente usadas para se referir a um grupo de coisas" (TAGNIN, 2013, p. 74), como em um rebanho de bois.

No âmbito do ensino e aprendizado de $L E$, a competência comunicativa é caracterizada não apenas como um processo dinâmico de negociação de sentido entre os falantes de determinada língua (SAVIGNON, 1983), mas também como o "[...] conhecimento, ou competência, e a capacidade para pôr em prática ou executar essa competência em um uso de língua adequado e contextualizado ${ }^{7 \prime}$ (BACHMAN, 1995, p. 107, tradução nossa), no qual fatores como a finalidade da comunicação e os actantes envolvidos são levados em consideração (LLOBERA, 1995). Partindo desse prisma, há a necessidade de compreendermos os processos linguísticos que subjazem a competência comunicativa de falantes de língua não materna, tanto no que diz respeito a suas competências gramatical, textual, elocutiva, sociolinguística e estratégica (HYMES, 1972), como também a colocacional, cuja definição elenca o

[...] conhecimento ou habilidade dos aprendizes de inglês língua estrangeira/inglês segunda língua de reconhecer quais palavras coocorrem com frequência ao lado de outras palavras dentro de um contexto específico, como em livros especializados, artigos científicos ou relatórios técnicos em uma página de internet ${ }^{8}$ (WU, 2003, p. 96, tradução nossa).

O'Dell e McCarthy (2008) declaram que falantes não-nativos nem sempre conhecem a combinação de palavras adequada para exprimir ideias específicas em $L E$, como é o caso das expressões inserir o cartãoe *meter o cartão. Pelo prisma fraseológico, a primeira estrutura contempla elementos socialmente convencionados em uma estrutura lexicalizada. Como prova disso, uma busca rápida no sítio eletrônico Linguee ${ }^{9}$ nos

\footnotetext{
7 [...] conocimiento, o competencia, y la capacidad para poder en práctica o ejecutar esa competencia en un uso de la lengua adecuado y contextualizado.

${ }^{8} \mathrm{EFL} / \mathrm{ESL}$ learner's knowledge or ability to recognize which words co-occur frequently with other words within a specific context, such as professional textbooks, research articles, or technical reports on a website.
} 
apresentará dezenas de exemplos de uso da colocação inserir o cartão, ao passo de que a palavra meter, por não realizar uma colocação válida nesse contexto em língua portuguesa, elencará ocorrências de estruturas livres ou não restritas.

Nesse cenário, considerando as colocações como um constante problema de aprendizagem de LE (GASS; SELINKER, 1994), Fillmore (1979) compara os falantes nãonativos em estágios iniciais de aprendizagem a falantes ingênuos, isto é, os indivíduos que não conhecem os lexemas e frases idiomáticas, as combinações lexicais que não estejam baseadas em relações de significado, as imagens metafóricas de determinada língua, entre outros. Como reflexo deste desconhecimento,

[...] Qualquer análise da fala ou escrita de aprendizes revela uma deficiência dessa competência colocacional. Falta de competência nessa área força os alunos a cometerem erros gramaticais por terem que produzir sentenças mais longas pelo fato de não conhecerem colocações que expressam acuradamente o que eles querem dizer ${ }^{10}$ (LEWIS, 2000, p. 49, tradução nossa).

O excerto mencionado se desdobra em dois aspectos, nomeadamente, a produção de sentenças livres como estratégia linguística para suprir a falta de conhecimento lexical, e a noção de erro atrelada à aprendizagem de LE. Sobre o primeiro, consideremos a competência estratégica, cuja utilização decorre da compensação das falhas na comunicação devido a fatores como a incapacidade de lembrar uma ideia ou uma forma gramatical e a falta de conhecimento acerca de uma ou mais áreas da competência comunicativa (CANALE, 1995). De igual modo, a produção de sentenças livres pode resultar em um mal-entendido durante o ato comunicativo (GASS; SELINKER, 1994) e na ocorrência de estruturas agramaticais nos discursos de falantes não-nativos, cuja problemática acomoda a discussão acerca da palavra erro

[...] oriunda das mesmas concepções do que é "certo ou errado" que circulam em nossa sociedade, logo, pode notar que no decorrer da história esta noção está atrelada a questões socioculturais resultantes da visão de mundo, juízos de valores e ideologias que no transcorrer do tempo sofrem mudanças significativas (SANTANA JUNIOR; PINTO; SANTANA, 2011, p. 6).

\footnotetext{
${ }^{9}$ Endereço eletrônico em: $\underline{\text { http://www.linquee.com.br }}$

${ }^{10}$ Any analysis of students' speech or writing shows a lack of this collocational competence. Lack of competence in this area forces students into grammatical mistakes because they create longer utterances because they do not know the collocations which express precisely what they want to say.
} 
O conceito de erro está centrado nas dicotomias entre certo e errado, língua e fala, gramatical e agramatical, adequado e não-adequado, entre outros (BRITTO, 1997), é perpassado por questões políticas, sociais e culturais (SANTANA JUNIOR; PINTO; SANTANA, 2011), e reflete o preconceito linguístico das classes majoritárias sobre as minoritárias (GOMES, 2016). Entretanto, em uma perspectiva não normativa,

[...] os então considerados "erros" de aquisição em PLE (ou em língua estrangeira, tanto falada quanto escrita) nada mais são que 'desvios' da forma alvo, da forma esperada, institucionalizada, ou convencional, devido às hipóteses que os aprendizes testam a partir de seus conhecimentos em L1 (MAIA, 2009, p. 2).

Visto dessa forma, a utilização do termo desvio, em qualquer âmbito de análise linguística, como no fonológico e no lexical, em detrimento de erro, acomoda a descrição dos processos e das estratégias empregadas durante a aprendizagem. Destarte, e em harmonia com Firth (1978), os desvios não podem mais ser entendidos como uma falha de aprendizagem, mas sim como indícios de como os aprendizes testam suas hipóteses acerca do sistema linguístico da língua não materna.

\section{Os processos de interlíngua}

Tratamos dos desvios colocacionais evidenciados nas produções escritas de aprendizes de PLE à luz do conceito de Interlíngua, referente ao sistema linguístico intermediário entre a língua materna e a segunda língua (AL-KHRESHEH, 2015), o qual apresenta "[...] seus próprios conjuntos de regras, que podem ser de natureza fonológica, morfológica, sintática, semântica e pragmática" (SILVA NETTO, 2016, p. 56), observável na tentativa de comunicação na língua alvo (SELINKER, 1974), conforme figura 1.

Figura 1 - Esquema de interlíngua

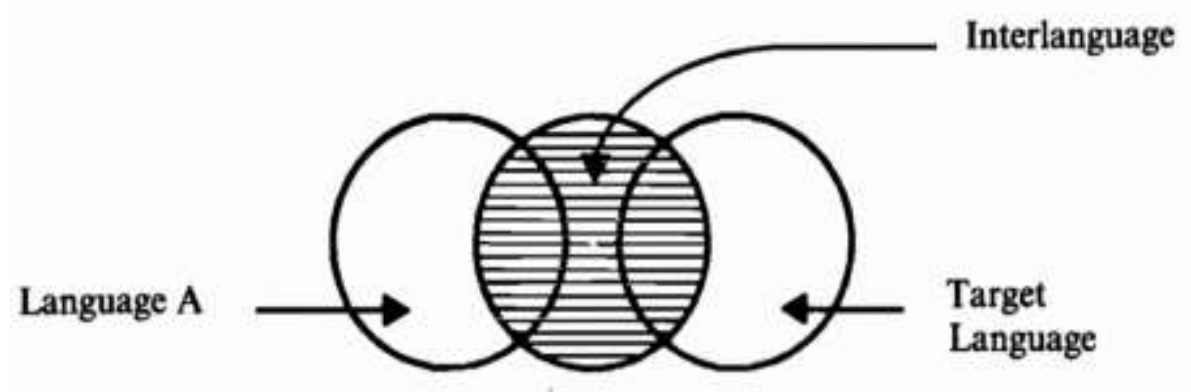

Fonte: Corder (1974, p. 162).

Investigar os desvios colocacionais atrelados à descrição desses sistemas 
linguísticos intermediários se faz relevante pois, durante o processo de aprendizagem de uma língua não materna, os aprendizes tendem a

[...] perceber certas unidades lexicais como idênticas na sua língua materna, interlíngua e língua alvo. Então, por exemplo, eles podem entender que 'table', na sua língua materna, é o mesmo que 'mesa' na língua alvo, e desenvolver um sistema de interlíngua no qual mesa pode (erroneamente nos padrões da língua alvo) ser usado em expressões como 'table of contents', 'table the motion' e assim por diante ${ }^{11}$ (TARONE, 2006, p. 749, tradução nossa).

Do ponto de vista lexical, o excerto citado anteriormente ilustra a forma como generalizações ocorrem na produção em LE. O processo de interlíngua evidenciado demonstra a transposição do significado de table para a colocação table of contents, cuja tradução equivale a sumário. Selinker (1974) apresenta outro contexto no qual os desvios colocacionais são salientes, a saber, na utilização do verbo drive, cuja colocação ocorre com a maioria dos meios de transporte, como em drive a car/bus, com exceção do substantivo bicycle. Interessa-nos, portanto, descrever os desvios colocacionais em PLE a partir dos cinco processos de interlíngua descritos a seguir.

Se podemos demonstrar experimentalmente que itens, regras e subsistemas fossilizados que ocorrem na produção da IL são resultados da L1, então estamos lidando com o processo de transferência linguística; se esses itens, regras e subsistemas fossilizados são resultados de itens identificáveis nos procedimentos de ensino, estamos lidando com o processo conhecido como transferência de instrução; se eles são resultados da abordagem do material ao qual o aprendiz estuda, então estamos lidando com estratégias de aprendizagem de segunda língua; se eles são resultados da abordagem comunicativa do aprendiz com falantes nativos da língua alvo, então estamos lidando com estratégias de comunicação em segunda língua; e finalmente, se eles são resultados de uma clara supergeneralização das regras [gramaticais] e semânticas da língua alvo, então estamos lidando com a supergeneralização do material linguístico da língua alvo ${ }^{12}$ (SELINKER, 1974, p. 37, tradução nossa, grifos

\footnotetext{
${ }^{11}$ [...] perceive certain units as the same in their $\mathrm{NL}, \mathrm{IL}$, and TL. So, for example, they may perceive $\mathrm{NL}$ 'table' as exactly the same as TL 'mesa,' and develop an interlanguage in which mesa can (erroneously in terms of the TL) be used in expressions like 'table of contents,' 'table the motion' and so on.

12 If it can be experimentally demonstrated that fossilizable items, rules and subsystems which occur in IL performance are a result of the $\mathrm{NL}$, then we are dealing with the process of language transfer, if these fossilizable items, rules, and subsystems are a result of identifiable items in training procedures, then we are dealing with the process known as transfer of training, if they are a result of an identifiable approach by the learner to the material to be learned, then we are dealing with strategies of second language learning; if they are a result of an identifiable approach by the learner to communication with native speakers of the $\mathrm{TL}$, then we are dealing with strategies of second language communication; and finally, if they are a result of a clear overgeneralization of TL rules and semantic features, then we are dealing with the overgeneralization of TL linguistic material.
} 
do autor).

O primeiro processo de interlíngua sobre o qual tratamos diz respeito à transferência linguística, cuja definição engloba as interferências da língua materna na produção da LE. Tomemos por base a ordem na qual os substantivos e os adjetivos assumem em língua portuguesa e inglesa. Falantes nativos do português, em estágios iniciais de aprendizagem do inglês, frequentemente produzem sentenças como *This is a car blue, por transferirem o sistema sintático substantivo + adjetivo da língua portuguesa. Com efeito, as ocorrências desse processo de interlíngua podem ser analisadas tanto no nível da sintaxe, como também da fonologia, do léxico, dentre outros. Henderson (1985), por sua vez, afirma que à medida que o aprendiz se torna mais proficiente, ou seja, se torna mais comunicativamente competente, menos ocorrências de transferência linguística irá apresentar na sua produção na LE.

O segundo processo de interlíngua é intitulado de transferência de instrução, ou desvios induzidos (TARONE, 2006), e está associado às práticas de sala de aula, ao plano de curso e ao material didático. Em seu estudo sobre a aprendizagem de inglês por alunos croatas, Selinker (1974) declara que, muito embora esses aprendizes saibam a diferença entre os pronomes pessoais he she, suas produções textuais mostram ocorrências nas quais o pronome he faz referência aos gêneros masculino e feminino. O autor argumenta que esses desvios decorrem da maneira como o material didático apresenta os conteúdos, favorecendo exclusivamente a utilização do pronome he, em detrimento de uma exposição equitativa entre os pronomes he she.

As estratégias de aprendizagem de segunda língua compõem o terceiro processo de interlíngua e são relacionadas aos contextos sociais da língua materna. Selinker (1974, p. 39, tradução nossa) declara que "em muitas culturas tradicionais, o canto é utilizado como um dispositivo de aprendizado, relacionando-se claramente com o que é aprendido nessas situações ${ }^{13 "}$. Outro exemplo dessa estratégia pode ser descrito a partir da maneira como as falhas de aprendizagem são percebidas na cultura japonesa. No Japão, ao invés de os alunos tirarem suas dúvidas com os professores, é comum que prefiram consultar dicionários ou outros alunos, por medo de que a sociedade os considere incapazes de aprender (BUTLER-TAKANA, 2000).

13 In many traditional cultures, chanting is used as a learning device, clearly relating to what is learned in those situations. 
O quarto processo, estratégias de comunicação em segunda língua, na ótica de Gass e Selinker (1994) compreende três etapas, a saber, o momento no qual o aprendiz reconhece que tem problemas de comunicação - problematização; a tentativa de buscar formas de sanar seus problemas - conscientização; e o conhecimento acerca dos objetivos comunicativos almejados na LE - intencionalidade. Contudo, gostaríamos de incorporar a noção de competência estratégica ao processo de interlíngua em discussão, uma vez que

Se um aprendiz quer fazer referência a um cabo elétrico em inglês e não conhece o item lexical exato para nomeá-lo, ele pode chamá-lo de 'tubo', 'um tipo de cordão que você usa para coisas elétricas cujo nome eu não sei' ou 'um fio com duas entradas em cada lado ${ }^{14 \prime}$ (TARONE, 2006, p. 749, tradução nossa).

Em harmonia com o excerto mencionado anteriormente, o quarto processo entra em cena quando um aprendiz de uma língua não materna tenta se comunicar sem ter conhecimento linguístico, por vezes lexical, que the permita realizar a tarefa. Ressaltamos que, muito embora essa estratégia de comunicação em segunda língua seja vantajosa por viabilizar que os aprendizes se comuniquem na $L E$, ela pode trazer desvantagens, como na maior probabilidade de ocorrências de desvios por decorrência da produção de sentenças mais longas. Assim, a adoção de sentenças longas, como em um tipo de cordão que você usa para coisas elétricas cujo nome eu não sei, em detrimento da forma convencionada cabo elétrico, nos revela a falta de conhecimento colocacional na LE.

O último processo de interlíngua sobre o qual versamos, a supergeneralização do material linguístico da língua alvo, é evidente não apenas em contexto de aprendizagem, mas também durante as etapas de aquisição da língua por crianças, pois é uma "[...] clara evidência do processo, no sentido de que mostra que o aprendiz dominou as regras da língua alvo, mas também mostra que há muito a aprender ${ }^{15 "}$ (TARONE, 2006, p. 749, tradução nossa). Em outros termos, esse processo pode tanto revelar se o aprendiz conhece as regras inerentes à $L E$, como também pode indicar seu desconhecimento acerca de como e em quais contextos tais regras são aplicáveis ou não. Selinker (1974)

\footnotetext{
${ }^{14}$ If the learner wants to refer to an electrical cord in English and does not know the exact lexical item to use in referring to it, he can call it 'a tube', 'a kind of corder that you use for electric thing I don't exactly the name' or 'a wire with eh two plugs in each side'.

15 [...] clear evidence of process, in that it shows that the learner has mastered a target language rule, but it also shows what the learner has yet to learn.
} 
ilustra a supergeneralização a partir do morfema -ed para formar o passado dos verbos regulares em língua inglesa, como em (i) *drinked, *hitted, *goed e (ii) *what did he intended to say? configurando, dessa forma, desvios quanto à transposição da regra dos verbos regulares para os verbos irregulares e à utilização de auxiliares no passado simples, respectivamente.

Encerramos essa seção enfatizando que os cinco processos de interlíngua descritos são centrais para o estudo dos desvios colocacionais em PLE. Entretanto, a fronteira entre esses processos nem sempre é nítida, havendo a possibilidade de ocorrência de múltiplos mecanismos no discurso do falante não-nativo.

\section{Metodologia}

O design metodológico desta pesquisa é de caráter qualitativo e descreve os desvios colocacionais evidenciados nas produções textuais de oito participantes norteamericanos, de níveis de proficiência compreendidos entre B1/B2 e C1/C2, conforme quadro 1. Além disso, o presente estudo foi submetido e aprovado pelo Conselho de Ética da Universidade Federal do Ceará, via Plataforma Brasil, possuindo o respectivo CAAE de número 54172616.1.0000.5054.

Quadro 1 - Perfil dos participantes

\begin{tabular}{c|c}
\hline Nível de proficiência & Quantidade de participantes \\
\hline B1/B2 & 4 \\
C1/C2 & 4 \\
\hline
\end{tabular}

Fonte: Adaptado de Silva Netto (2016, p. 69).

Os participantes, conhecidos como English Teaching Assistants, bolsistas do programa FLTA - Foreign Language Teaching Assistants, da Comissão Fulbright, desenvolveram atividades de promoção da língua inglesa em território nacional por exatos nove meses em 2015. Seus níveis de proficiência estão em conformidade com os descritores do Quadro Comum Europeu de Referência para as Línguas para a habilidade escrita. Vide o quadro 2.

Quadro 2 - Descritores para a produção escrita PRODUÇÃO ESCRITA GERAL

C2 É capaz de escrever textos complexos com clareza e fluência, num estilo adequado e eficaz, com uma estrutura lógica que ajuda o leitor a identificar as questões pertinentes. 
C1 É capaz de escrever textos bem estruturados, com clareza, sobre assuntos complexos, sublinhando as questões relevantes e mais salientes, desenvolvendo e defendendo pontos de vista, acrescentando informações complementares, razões e exemplos pertinentes, e concluindo adequadamente.

B2 É capaz de escrever textos pormenorizados, com clareza, acerca de vários assuntos relacionados com os seus interesses, sintetizando e avaliando informações e argumentos recolhidos em diversas fontes.

B1 É capaz de escrever textos coesos e simples acerca de um leque de temas que lhe são familiares, relativos aos seus interesses, ligando uma série de elementos pequenos e discretos para formar uma sequência linear.

Fonte: Adaptado de BRITISH COUNCIL (2001, p. 96).

Como instrumento de coleta de dados, elaboramos cinco propostas de produção textual, dispostas no quadro 3, enviadas por e-mail aos participantes, cujos assuntos integram suas perspectivas sobre o Brasil, como os pontos turísticos, a cultura e a culinária. Ressaltamos, de igual modo, que as propostas se enquadram no gênero e-mail e, além disso, estipulamos um período de dois meses para que os participantes pudessem cumprir com o processo de escritura de seus textos.

\section{Quadro 3 - Propostas de produção textual}

1. Você recebeu um e-mail de sua amiga americana. Ela diz que lhe fará uma visita em breve. Responda ao e-mail dando sugestões de lugares turísticos que vocês possam visitar na sua cidade brasileira.

2. Sua amiga está se planejando para visitá-lo no Brasil. Ela escreveu outro e-mail pedindo direções do aeroporto até sua casa e da sua casa até a universidade em que você trabalha. Responda ao email explicando o trajeto para a sua amiga.

3. Sua amiga, por ser muito curiosa, Ihe envia outro e-mail perguntando sobre as comidas típicas da sua cidade. Responda ao e-mail contando para a sua amiga sobre as suas experiências com a comida brasileira.

4. Sua amiga escreveu um e-mail para você perguntando sobre os costumes no Brasil, pois ela não sabe quase nada sobre a cultura brasileira. Responda ao e-mail contando para a sua amiga sobre as suas experiências culturais no Brasil e se as suas expectativas sobre a cultura brasileira foram atendidas ou não.

5. O último e-mail de sua amiga trata das lembrancinhas que ela pode comprar no Brasil. Responda ao e-mail indicando locais onde ela possa comprar lembrancinhas para dar aos seus amigos e familiares americanos.

Fonte: Adaptado de Silva Netto (2016, p. 70).

Os dados foram gerados mediante a análise das produções textuais dos participantes e dispostos conforme os respectivos níveis de proficiência em PLE, apresentados no quadro 1. Durante a análise, as ocorrências de desvios colocacionais foram identificadas, classificadas e descritas, cuja apreciação é dada na próxima seção.

\section{Análise dos dados}

Esta seção discute as ocorrências de desvios colocacionais evidenciadas no corpus da pesquisa, provenientes das produções textuais dos oito participantes norte- 
americanos. Essa análise, de cunho qualitativo, apresenta não apenas a forma como os aprendizes de PLE criam hipóteses acerca da língua alvo, mas também os padrões de interlíngua pertinentes à aprendizagem de colocações.

Os desvios aqui apresentados estão embasados nos cinco processos centrais de interlíngua de Selinker (1974) e nas ocorrências de outros processos que emergiram a partir de nossa análise. Assim sendo, destacamos que a apreciação dos desvios colocacionais é realizada de acordo com os níveis de proficiência dos participantes e que os processos de interlíngua descritos podem se sobrepor.

\section{Quadro 4 - Desvio colocacional no nível B1/B2}

Quando você chegar pode comprar passeios para as piscinas naturais e passeios de barco aparte. Também, tem muitos bares onde você pode descansar e tomar as comidas regionais. Neste passeio, você tem a oportunidade de passar a tarde numa das praias mais lindas daqui.

\section{Fonte: Adaptado de Silva Netto (2016).}

O quadro 4 elenca um desvio colocacional quanto à transferência linguística e à supergeneralização do material linguístico da língua alvo. Assim, a ocorrência em discussão está fundamentada nas diferenças entre os verbos empregados antes de vocabulários de comida, tanto em português como em inglês. Em língua inglesa, as combinações verbais atreladas a vocabulário de comida podem ser descritas em eat pizza/meat/lunch e drink water/soda/beer, pois os colocados são alimentos sólidos e líquidos, respectivamente. No entanto, há a possibilidade de o verbo have encapsular eat e drink, formando combinações como have pizza/meat/water/beer. Em contrapartida, em língua portuguesa, a mesma relação entre alimentos sólidos e líquidos é dada, de forma geral, pelos verbos comer pizza/carne e beber água/cerveja.

O desvio destacado na ocorrência em discussão decorre da alta frequência na qual o verbo have encapsula eat e drink em língua inglesa. Em conformidade com o corpus das 5,000 palavras mais recorrentes em inglês disponibilizado pelo sítio eletrônico Word Frequency Data ${ }^{16}$, na categoria 130 (Home and Health), as palavras have, eat e drink possuem frequência respectiva à 172.472, 11.926 e 2.531 dos casos. Dessa forma, pelo fato de have ser mais recorrente, a escolha do participante em utilizar o verbo tomar como forma de abranger os alimentos sólidos em língua portuguesa é um processo de

\footnotetext{
${ }^{16}$ Disponível em: https://www.wordfrequency.info/samples.as. Acesso: 23/12/2021.
} 
transferência linguística. De igual modo, essa ocorrência também se enquadra no processo de interlíngua de supergeneralização do material linguístico da língua alvo, haja vista que o participante buscou utilizar o verbo tomar em um contexto no qual a regra de alimentos sólidos não é aceitável.

Quadro 5 - Desvios colocacionais no nível C1/C2

(i) Felizmente, você vai estar aqui durante a abertura de Natal, que terá lugar no dia 28 de novembro à noite no centro da cidade. Nunca assisti, mas pelo que me disseram é uma das mais lindas celebrações de Natal do sul do Brasil e muitas pessoas vêm de outras cidades para assistir.

(ii) Muitos gastam muito dinheiro e tempo nos procedimentos de embelezamento, e todos sempre estão "produzidos", como dizem aqui: não saem de casa sem pintar as unhas, sem vestir saltos ou sem se maquiar.

(iii) Eu levaria castanha de caju também, que é bom demais. Sobre vestuário, sei lá, eu quase sempre uso vestuário de praia. As decorações mais interessantes são da Amazônia.

(iv) Aqui em Pato Branco não tem muitos restaurantes chiques, mas tem um que é melhor do que os outros, chamado Água Doce. O serviço é ótimo, o ambiente é aconchegante, e tem uma boa relação entre a qualidade da comida e o preço.

(v) Infelizmente, o estereótipo de que há muita burocracia e desorganização tende a ser verdade, como bem descobri quando tive que fazer todos os formulários para me tornar um residente legal no Brasil.

(vi) Outra coisa que não esperava foi a preocupação com a aparência física. Muitos gastam muito dinheiro e tempo nos procedimentos de embelezamento, e todos sempre estão "produzidos" [...]

(vii)Tem o Mercado Central no centro, mas meu lugar favorito é a feirinha de beira mar. Tem de tudo! Tem chaveiros, ímãs, cartas postais e mais! Aí, vc tbm pode comprar cachaça e castanha, que são coisas muito típicas daqui!

Fonte: Adaptado de Silva Netto (2016).

A ocorrência (i), associada ao processo de transferência linguística evidencia a criação da hipótese de que a colocação take place, em língua inglesa, exprime o mesmo sentido de *terá lugar, em português. Essa relação direta entre os termos colocacionais em ambas a línguas destaca a falta de conhecimento lexical da palavra acontecer ou ocorrer.

O caso (ii) deriva de colocações, em língua inglesa, com o verbo wear seguido de vocabulário sobre roupas e acessórios, como em wear a shirt, wear glasses e wear perfume. Entretanto, em língua portuguesa, a escolha do verbo é dependente do substantivo que o segue, formando colocações como vestir uma camisa, usar óculos e passar perfume, respectivamente. Com isso em mente, a ocorrência (ii) foi classificada 
como um desvio colocacional quanto à transferência linguística pelo fato de vestir saltos empregar o verbo vestir e não usar. Na mesma nota, podemos argumentar que o processo de supergeneralização do material linguístico entra em cena nessa ocorrência, por aplicar o verbo vestir a um contexto que não o cabe.

No caso (iii), observamos o desvio colocacional quando à transferência linguística em vestuário de praia. Acreditamos que a motivação para esse desvio teve como base a palavra composta em língua inglesa beachwear, cujos elementos em português são, respectivamente, praia e roupa/vestuário. Entretanto, a colocação não se constitui com a palavra vestuário, e sim com roupa. De maneira geral, um falante nativo certamente entenderia a combinação vestuário de praia, mas buscaria outras formas de dizê-la, como em moda praia ou roupa de praia/banho.

De acordo com a ocorrência (iv), classificada como desvio quanto às estratégias de comunicação em segunda língua, nota-se o desconhecimento do participante acerca da colocação (relação) custo-benefício e, por esse motivo, a necessidade de estender seu discurso através de estruturas livres. Isso quer dizer que, em termos de competência colocacional, destacamos não apenas a maior chance de que falantes não-nativos cometam inadequações gramaticais ao ampliarem seu texto, mas também o risco de não se fazerem entender por falantes nativos.

O exemplo (v) se configura como um desvio colocacional no qual o emprego verbal não corresponde à estrutura convencionalizada em língua portuguesa, a saber, preencher formulários. Esse tipo de desvio, por ser característico de colocações, não está descrito nos processos de interlíngua de Selinker (1974). Por essa razão, faremos referência a esse desvio como o emprego equivocado de elementos colocacionais, em específico ao uso verbal, como na substituição equivocada do verbo preencher por fazer. Igualmente, não consideramos que a língua materna dos participantes tenha sido responsável pela troca verbal, pois, em inglês, utiliza-se os verbos fill in / fill out.

A ocorrência (vi) nos apresenta um desvio pautado no emprego equivocado de elementos colocacionais que, no caso em análise, destaca uma combinação de substantivos que não forma uma colocação válida em língua portuguesa. Desta forma, muito embora a combinação procedimentos de embelezamento seja compreensível para falantes nativos, essa não é a forma convencionalizada e não substitui tratamento de beleza.

E, por fim, o desvio colocacional em (vii) elenca o emprego equivocado do 
substantivo carta, que não forma colocação com postal. Para que o sentido seja preservado, a associação adequada de palavras é expressa em cartão postal.

À guisa de conclusão de nossa análise dos desvios colocacionais, averiguamos que a transferência linguística não se constitui como o único processo de interlíngua presente nos discursos dos participantes de ambos os níveis B1/B2 e C1/C2. De igual modo, constatou-se que o maior volume de desvios colocacionais é oriundo dos níveis de proficiência mais avançados, fato esse que corrobora a literatura em interlíngua. Henderson (1985) aponta que, à medida que falantes não-nativos aprendem uma $L E$, alguns desvios provenientes de transferências linguísticas são substituídos por outros tipos de desvio, tais como os elencados em nossa análise. Outrossim, os dados apresentados revelam as hipóteses criadas pelos participantes sobre as colocações em língua portuguesa durante seu processo de aprendizado, como na ocorrência tomar comidas regionais, cuja problemática envolve questões lexicais de tomada de decisão acerca dos verbos seguidos por alimentos líquidos e sólidos. Teoricamente, em estágios mais avançados de aprendizagem, o participante que produziu essa estrutura perceberá que essa combinação de palavras não é convencionalizada, ou seja, não é "do jeito que a gente diz".

\section{Considerações finais}

Neste artigo, discutimos a noção de competência colocacional, cuja definição acomoda o reconhecimento e o uso desses itens lexicais em contextos reais de comunicação, e os desvios colocacionais evidenciados nas produções textuais em PLE.

Os dados obtidos são reveladores não somente de aspectos linguísticos dos discursos dos participantes, mas também das frequentes comparações entre as culturas americana e brasileira e das ideias pré-concebidas que os participantes possuíam antes de chegarem em território nacional. As análises também propiciaram a apreciação do estágio de interlíngua dos aprendizes de PLE, sob o prisma do desenvolvimento da competência colocacional. Em termos mais específicos, o grupo B1/B2 apresentou poucos desvios colocacionais, sendo eles classificados quanto à transferência linguística e à supergeneralização do material linguístico na língua alvo. 0 grupo $\mathrm{C} 1 / \mathrm{C} 2$, por sua vez, explicitou desvios colocacionais baseados nas interferências linguísticas e nos empregos equivocados de elementos verbais e nominais. Essa constatação é consistente com a 
literatura especializada na qual as hipóteses lançadas sobre a LE nos dão indícios de como as estruturas linguísticas são aprendidas e como o léxico mental é organizado.

As perspectivas de pesquisas futuras sobre essa temática podem explorar a forma como aprendizes de PLE, compreendidos no nível de proficiência $A 1 / A 2$, produzem colocações em textos reais e quais desvios colocacionais emergem dessas produções. $\mathrm{Na}$ mesma nota, trabalhos porvindouros podem potencialmente analisar os desvios colocacionais na ótica das produções orais de textos, com participantes de distintos níveis linguísticos.

\section{Referências}

AL-KHRESHEH, Mohammad Hamad. A review study of interlanguage theory. International Journal of Applied Linguistics \& English Literature, Footscray, v. 4, n. 3, p. 123-131, 2015.

BACHMAN, Lyle. Habilidad lingüística comunicativa. In: LLOBERA, Miquel. (org.). Competencia comunicativa: documentos básicos en la enseñanza de lenguas extranjeras. Madrid: Edelsa, 1995. p. 105-127.

BAHNS, Jens. Lexical collocations: a contrastive view. ELT Journal, Oxford, v. 11, p. 5663, 1993.

BRITTO, Luiz Percival Leme. $A$ sombra do caos: ensino de línguas x tradição gramatical. São Paulo: Mercado de Letras, 1997.

BUTLER-TAKANA, Paul. Fossilization: a chronic condition or is consciousness-raising the cure? 2000. Dissertation (Master's in Arts) - University of Birmingham, Faculty of Arts, Birmingham, 2000.

CANALE, Michael. De la competencia comunicativa a la pedagogía comunicativa del lenguaje. In: LLOBERA, Miquel. (org.). Competencia comunicativa: documentos básicos en la enseñanza de lenguas extranjeras. Madrid: Edelsa, 1995. p. 63-81.

CARTER, Ronald. Vocabulary: applied linguistic perspectives. London: Routledge, 1987.

BRITISH COUNCIL. Quadro europeu comum de referência para as línguas: aprendizagem, ensino e avaliação. Lisboa: Edições ASA, 2001.

CORDER, Stephen Pit. Idiosyncratic dialects and error analysis. In: RICHARDS, James Clifton (org.). Error analysis: perspectives on second language acquisition. London: Longman, 1974. p. 158-171.

FIRTH, May B. Interlanguage theory: implications for the classroom. McGill Journal of Education, Montréal, v. 13, n. 2, p. 155-165, 1978.

FILLMORE, Charles J. Innocence: a second idealization for linguistics. Proceedings of the Berkeley Linguistics Society, Berkeley, v. 5, p. 63-76, 1979. 
GASS, Susan M.; SELINKER, Larry. Second language acquisition: an introductory course. New Jersey: Lawrence Erlbaum, 1994.

GOMES, Marcela de Lima. As noções do termo erro para os estudos linguísticos e suas implicações ao ensino de língua portuguesa. 2016. Dissertação (Mestrado em

Educação) - Universidade Federal do Oeste do Pará, Instituto de Ciências da Educação, Santarém, 2016.

HENDERSON, Michael M. T. The notion of interlanguage. Journal of Modern Language Learning, Kansas, v. 21, p. 23-27, 1985.

HUNDT, Christine. Construções de verbo + substantivo: estrutura, semântica e posição dentro da fraseologia. Verbo e estruturas frásicas. Revista da Faculdade de Letras, Línguas e Literaturas, Porto, p. 267-275, 1994.

HYMES, Dell Hathaway. On communicative competence. In: PRIDE, J. B.; HOLMES, J. (org.). Sociolinguistics. selected readings. Harmondsworth: Penguin, 1972. p. 269-293.

LEWIS, Michael. Teaching collocations. further developments in the lexical approach. Hove: Language Teaching Publications, 2000.

LEWIS, Michael. The lexical approach: state of ELT and a way forward. $4^{\text {th }}$ ed. London: Language Teaching Publications, 2012.

LLOBERA, Miquel. Una perspectiva sobre la competencia comunicativa y la didáctica de las lenguas extranjeras. In: LLOBERA, Miquel (org.). Competencia comunicativa: documentos básicos en la enseñanza de lenguas extranjeras. Madrid: Edelsa, 1995, p. 5-26.

MAIA, Francisca Paula Soares. O "erro" linguístico a partir de uma perspectiva sociolinguística laboviana. In: CIEL - CICLO DE ESTUDOS EM LINGUAGEM. ESTUDOS DA LINGUAGEM E FORMAÇÃO DOCENTE: DESAFIOS CONTEMPORÂNEOS, 5., 2009, Ponta Grossa. Anais [...]. Ponta Grossa: UEPG, 2009.

O'DELL, Felicity; McCARTHY, Michael. English collocations in use, advanced: how words work together for fluent and natural English. Cambridge: Cambridge University Press, 2008.

SANTANA JUNIOR, Valdson José; PINTO, Marie Jolly Nascimento; SANTANA, Robson Ferreira. Erro(s): entre o desvio e a norma. In: COLÓQUIO INTERNACIONAL "EDUCAÇÃO E CONTEMPORANEIDADE", 5., 2011, São Cristóvão. Anais [...]. São Cristóvão: EDUCON, 2011. p. 1-16.

SAVIGNON, Sandra Joy. Communicative competence: theoretical and classroom practice. Reading: Addison-Wesley Publishing, 1983.

SELINKER, Larry. Interlanguage. In: RICHARDS, James Clifton (org.). Error analysis: perspectives on second language acquisition. London: Longman, 1974. p. 31-54.

SILVA NETTO, José William. Desenvolvimento da competência colocacional na produção escrita dos assistentes de professores de inglês em universidades brasileiras. 2016. 
Dissertação (Mestrado em Linguística) - Universidade Federal do Ceará, Centro de Humanidades, Fortaleza, 2016.

SINCLAIR, John. Collocation: corpus, concordance, collocation. Oxford: Oxford University Press, 1991.

TAGNIN, Stella E. O. O jeito que a gente diz: combinações consagradas em inglês e português. São Paulo: Disal, 2013.

TARONE, Elaine. Interlanguage. Amsterdam: Elsevier, 2006.

WU, Wen-shuenn. A quantitative study of university students' collocational competence in a ESP context. ESP Malaysia, Volume 9, 2003.

Submetido em: 11 jul. 2021. Aceito em: 28 jul. 2021. 